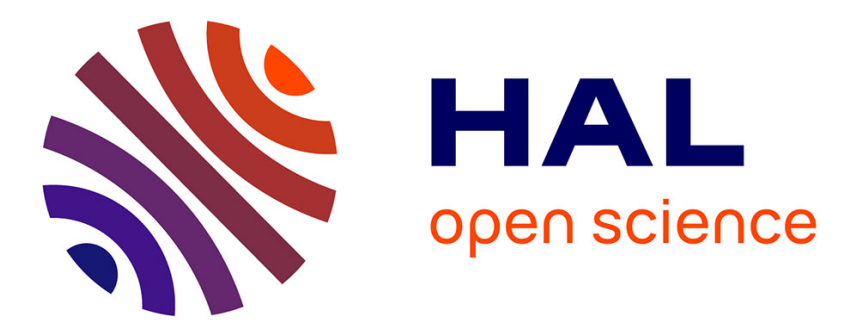

\title{
Simultaneous Photografting of Two Organic Groups on a Gold Surface by using Arylazo Sulfones as Single Precursors
}

Jérôme Médard, Philippe Decorse, Claire Mangeney, Jean Pinson, Maurizio Fagnoni, Stefano Protti

\section{To cite this version:}

Jérôme Médard, Philippe Decorse, Claire Mangeney, Jean Pinson, Maurizio Fagnoni, et al.. Simultaneous Photografting of Two Organic Groups on a Gold Surface by using Arylazo Sulfones as Single Precursors. Langmuir, 2020, 36 (11), pp.2786-2793. 10.1021/acs.langmuir.9b03878 • hal-03098486

\section{HAL Id: hal-03098486 https://hal.science/hal-03098486}

Submitted on 5 Jan 2021

HAL is a multi-disciplinary open access archive for the deposit and dissemination of scientific research documents, whether they are published or not. The documents may come from teaching and research institutions in France or abroad, or from public or private research centers.
L'archive ouverte pluridisciplinaire HAL, est destinée au dépôt et à la diffusion de documents scientifiques de niveau recherche, publiés ou non, émanant des établissements d'enseignement et de recherche français ou étrangers, des laboratoires publics ou privés.

\section{(1)(1) $\$(0)$}

Distributed under a Creative Commons Attribution - NonCommercial - ShareAlikel 4.0 


\title{
Simultaneous Photografting of Two Organic Groupson a Gold Surface by using Arylazo Sulfones As the Single Precursors.
}

\author{
Jérôme Médard, ${ }^{\dagger}$ Philippe Decorse, ${ }^{\dagger}$ Claire Mangeney, ${ }^{\dagger}$ Jean Pinson, ${ }^{\dagger *}$ Maurizio Fagnoni, ${ }^{\dagger}$ Stefano Protti ${ }^{* *}$ \\ † Université de Paris, ITODYS, CNRS, UMR 7086, 15 rue J-A de Baif, F-75013 Paris, France. \\ ${ }^{\ddagger}$ PhotoGreen Lab, Department of Chemistry, University of Pavia, Viale Taramelli 12, 27100 Pavia, Italy
}

\section{Abstract}

Arylazo sulfones have been exploited as photoactivable substrates for the simultaneous photografting of both aryl and methanesulfonyl groups on a gold surface. The obtained samples have been characterized by different spectroscopic techniques including Infrared reflection absorption (IRRAS), Surface-enhanced Raman (SERS), XPS spectroscopy and AFM.

\section{INTRODUCTION.}

The surface of many objects for industrial use or daily life is modified either for aesthetic purposes (plating of metals by chromium or gold), for preventing corrosion (painting of mild steel objects), or for adding new properties to a material (self-cleaning glasses). As concerning organic coatings, the simplest one is painting that protects a steel gate from rusting, but there is an interest in modifying surfaces with more strongly bonded organic films.

A significant example of the potentialities of surface modification in medicine is provided by stents insertion into arteries, where the release of an antimitotic agent (Paclitaxel for example) prevents restenosis. ${ }^{1,2}$ Binding of the drug on the metal surface must be strong enough to resist friction during implantation; this has been achieved by electrochemical reduction of a diazonium salt in the presence of butyl methacrylate, using the stainless steel stent as a cathode. $^{1, z}$

Several methods to obtain such strongly (covalently) bonded films are available. Selfassembled monolayers (SAMs) of silanes, ${ }^{3,4,5}$ and phosphonates, ${ }^{6}$ have been prepared on oxide surfaces, whereas alkenes and alkynes have been covalently bonded to hydrogenated silicon $^{7,8}$ or carbon. ${ }^{9}$ Analogously, long alkyl chain thiols SAMs have been attached to different metals, including $\mathrm{Au}, \mathrm{Ag}$ and $\mathrm{Cu} .{ }^{10}$ Electro-grafting strategies were also adopted in the presence of diazonium salts as grafting agents, able to provide aryl films covalently bonded to a variety of surfaces (carbon, metals, oxides, polymers). ${ }^{11,12}$

Photoinduced functionalization of surfaces by means of visible- or UV-light irradiation of benzoin derivatives, ${ }^{13}$ azobisisobutyronitrile ${ }^{14}$ and benzophenone ${ }^{15}$ was likewise exploited in radical-triggered polymerization. ${ }^{16}$ Benzophenone has been commonly used as a 
photoinitiator, since the biradical character of its triplet excited state, acts as a hydrogen atom abstractor to generate the radical responsible of the polymerization event. For example, the photografting of porous three-dimensional materials has been achieved via the benzophenone photoinitiated surface polymerization of 2-acrylamido-2-methyl-1-propanesulfonic acid within the pores of a macroporous polymer monolith contained in a fused silica capillary. ${ }^{17} \mathrm{In}$ another a hydrogen donor (the $N, N$-dimethyl aminophenyl group, DMA) was first electrografted on the surface, and benzophenone in solution was used as the photosensitizer to strip hydrogen from the grafted DMA. This system permitted efficient surface initiation of photopolymerization of 2-hydroxyethyl methacrylate. ${ }^{18}$

Short lived intermediates such as singlets or triplets carbenes and nitrenes presenting free doublets ${ }^{19}$ can be involved in insertion processes occurring into alkyl and aryl $\mathrm{C}-\mathrm{H}$ and $\mathrm{X}-\mathrm{H}$ $(\mathrm{X}=\mathrm{O}, \mathrm{N}, \mathrm{S})$ bonds for the surface modification of polymers. Among these species, diarylcarbenes, obtained by thermolysis or photolysis of the corresponding diazo compounds, have been investigated ${ }^{20}$ for the preparation of highly colored polystyrene beads. ${ }^{21}$

Diazonium salts $\left(A r-\mathrm{N}_{2}{ }^{+}\right)$or iodonium salts $\left(\mathrm{Ar}-\mathrm{I}^{+}-\mathrm{Ar}^{\prime}\right)$ under $\mathrm{UV}^{22}$ or visible light exposure (in the presence of a photoredox catalyst) ${ }^{23,24,25,26}$ cleave to aryl radicals that react with metals or polymers. In this way it was possible to pattern gold surfaces, ${ }^{24}$ polyethyleneterephthalate $(\mathrm{PET})^{25}$ or paper. $^{26}$

However, all the above reactions allow for the functionalization of the surface by a single chemical group obtained from the starting precursor. On the other hand, the preparation of mixed layers in order to enrich the surface chemistry has received less attention. As an example, mixed monomers providing charge transfer complexes such as styrene and vinyl acetate or maleic anhydride have been photografted to improve the surface properties of PET. $^{27,28}$ Two incompatible enzymes (trypsin and transglutaminase) were separately encapsulated into different poly(ethylene glycol) (PEG) network layer grafted on a polyethylene film via visible light induced living photografting polymerization. ${ }^{29}$ Electrografting also allows the preparation of mixed layers. Thus, a binary mixture of aryl diazonium salts bearing oppositely charged para substituents $\left(-\mathrm{SO}_{3}{ }^{-}\right.$and $\left.-\mathrm{N}\left(\mathrm{CH}_{3}\right)_{2}{ }^{+}\right)$has been electrografted and the surface ratio of the two phenyl groups is consistently 1:1 regardless of the ratio of the two aryl diazonium salts in the modification solutions. ${ }^{30}$ The grafting of the 1(bithien-2-yl)-4-benzenediazonium (BTB) salt complexed by $\beta$-cyclodextrin (CD) provides a layer of grafted BTB oligomers complexed by CD. When CD is removed from the surface, pinholes are created and the 4-nitrobenzenediazonium salt is reduced to graft a second component. ${ }^{31}$ Following the same strategy, after electrografting of the sterically hindered 4((triisopropylsilyl)ethynyl)phenyl groups, the cleavage of the isopropyl groups and further 
grafting of nitrophenyl groups also permits to obtain mixed aryl layers. ${ }^{32}$ Mixed layers of aminophenyl and perfluoroalkyl groups electrografted on carbon fibers (obtained from aryldiazonium salt and perfluoroalkyliodide) permit to obtained hydrophobic carbon-epoxy composites with improved mechanical properties. ${ }^{33}$ Mixed layers have also been prepared by combined electro and photografting: a multilayer film of nitrophenyl groups was electrografted to a carbon surface and 4-aminophenylazide was further photografted to this surface from a spin-coated solution. ${ }^{34}$

We present herein a protocol for the simultaneous gold surface modification by two different functional groups, starting from arylazo sulfones 1a-c as photoactivable precursors.

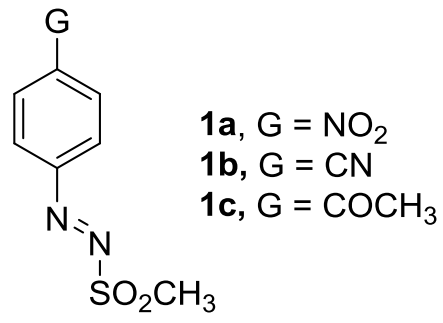

The presence of a dyedauxiliary group $-\mathrm{N}_{2} \mathrm{SO}_{2} \mathrm{CH}_{3}$ in such bench stable derivatives is responsible for both color and photoreactivity of the molecules that, when irradiated, undergo homolytic cleavage of the N-S bond, and the formation of the corresponding aryl radical (Ar $).{ }^{35}$ Such substrates have found recent application in organic synthesis, for the visible-light induced formation, under metal- and (photo)catalyst free conditions, of both C-C $\mathrm{C}^{36,37,38,39}$ and C-heteroatom bonds. ${ }^{40,41}$

In contrast, the use of arylazo sulfones in material chemistry received only few attentions in the past as the use of arylazo tosylsulfones as thermal initiators in the radical polymerization of acrylate monomers. ${ }^{42}$ In this paper we present the photografting of azosulfones and demonstrate that both substituents of the $\mathrm{N}=\mathrm{N}$ bond are effectively bonded to the surface.

\section{EXPERIMENTAL.}

Chemicals. Arylazo sulfones were prepared from the corresponding anilines by following a known method. ${ }^{43}$ Spectroscopical data of the compounds are in accordance with the literature. Dry and purified acetonitrile was obtained from a Pure Solv system from Innovative Technology.

Photografting was achieved by placing a gold plate in a test tube with a septum screw cap; the tube was filled with argon and a $0.1 \mathrm{mM}$ solution of the chosen azosulfone in ACN was deposited with a needle, through the septum, on the gold surface. Irradiation was performed using a Kessil Lamp (40 $\mathrm{W}, 456 \mathrm{~nm})$ as the light source for $8 \mathrm{~h}$ (Scheme 1). 


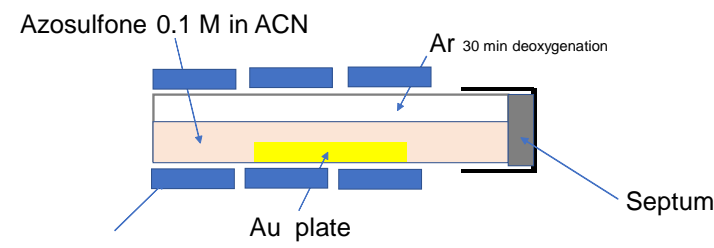

Kessil Lamp 40 W

Scheme 1. Experimental setup.

Substrates. Gold coated (100 nm) silicon wafers obtained from Sigma-Aldrich, were cut into $1 \times 1 \mathrm{~cm}^{2}$ pieces and successively rinsed in a bath of sulfuric acid (95\%) for $2 \mathrm{~s}$, and with distilled water and under sonication in distilled water, acetone, and absolute ethanol (380 s each) and finally dried by an argon stream.

Infrared reflection absorption spectroscopy (IRRAS). Spectra of modified plates were recorded using a purged (low $\mathrm{CO}_{2}$, dry air) Jasco FT/IR-6100 Fourier Transform InfraRed Spectrometer equipped with an MCT (mercury-cadmium-telluride) detector. For each spectrum, 1000 scans were accumulated with a spectral resolution of $4 \mathrm{~cm}^{-1}$. The background recorded before each spectrum was that of a cleaned substrate.

Surface-enhanced Raman spectroscopy (SERS). The SERS spectra were recorded on gold SERS substrates modified by arylazo sulfone using a Horiba XploRA PLUS Raman microscope with an excitation wavelength of $633 \mathrm{~nm}$ and a power of $0.6 \mathrm{~mW}$. The spectral resolution was less than $3 \mathrm{~cm}^{-1}$ and the accumulation time was set to $20 \mathrm{~s}$ with two repetitions.

XPS Spectra. XPS measurements were performed using a K-Alpha system (Thermo Fisher Scientific, East-Grinstead, UK) fitted with a microfocused and monochromatic Al $\mathrm{K} \alpha \mathrm{X}$-ray source (1486.6 eV, spot size: $400 \mu \mathrm{m}$ ). The pass energy was set to 150 and $40 \mathrm{eV}$ for the survey and the high-resolution spectra, respectively. The spectra were calibrated against the $\mathrm{C}-\mathrm{C} / \mathrm{C}-\mathrm{H} \mathrm{C} 1 \mathrm{~s}$ component set at $285 \mathrm{eV}$. The chemical composition was determined with version 5.9902 Avantage software, by using the manufacturer sensitivity factors. The spectra were calibrated against $\mathrm{C} 1 \mathrm{~s}$ set at $285 \mathrm{eV}$.

Contact Angle Measurements. The water interaction properties were characterized with a drop shape analysis system Krüss DSA30S and a Drop Shape Analysis 1.92.1.1 version software.

AFM Images. AFM images were recorded with a NT-MDT Solver pro equipment. AFM topography was performed in the intermittent contact mode with standard silicon cantilevers. Image analysis was achieved with the free software WSxM. 
IRRAS. After irradiation of the azosulfone solution deposited on a gold plate (in deoxygenated ACN), the plate was ultrasonicated for $180 \mathrm{~s}$ in EtOH and dried under argon, an IRRAS spectrum was recorded. The modified gold plates are referred as $A u-\mathrm{NO}_{2}, A u-\mathrm{CN}, A u-\mathrm{COCH}_{3}$. The IR and Raman spectra indicate the presence of the aromatic groups and also of the substituents $\left(\mathrm{NO}_{2}, \mathrm{CN}\right.$, $\left.\mathrm{C}(=\mathrm{O}) \mathrm{CH}_{3}\right)$, in the absence of irradiation these IR signals are not observed (Table 1, Figure 1). We also searched for the presence of azo bonds either as $A u-\mathrm{N}=\mathrm{N}-$ or as $-\mathrm{N}=\mathrm{N}$ - inside the film. The Ar$\mathrm{N}=\mathrm{N}-\mathrm{SO}_{2} \mathrm{Me}$ stretching bands are weak in the starting azosulfones $\left(1414,1404\right.$ and $1407 \mathrm{~cm}^{-1}$ for, respectively, 1a, 1b, 1c) and are not observed in $A u-\mathrm{NO}_{2}, A u-\mathrm{CN}, A u-\mathrm{COCH}_{3} \cdot{ }^{44} \mathrm{SO}_{2}$ stretching $\left(v_{\text {sym(SO2) }}\right.$ at $\left.c a .1110-1170 \mathrm{~cm}^{-1}\right)$ and bending $\left(\delta_{(\mathrm{SO} 2)}\right.$ at $\left.c a .325-365 \mathrm{~cm}^{-1}\right)$ vibrations ${ }^{45,46,47}$ cannot be safely assigned by IR while they clearly appear in the surface-enhanced Raman spectrum at $1174 \mathrm{~cm}^{-1}$ and $1363 \mathrm{~cm}^{-1}$ (Table 1, Figure 2).

Table 1. IR and Raman spectra of Au- $\mathrm{NO}_{2}, \mathrm{Au}-\mathrm{CN}, \mathrm{Au}-\mathrm{COCH}_{3}$, wavenumbers $\left(\mathrm{cm}^{-1}\right)$

\begin{tabular}{|c|c|c|c|c|c|c|}
\hline Azosulfones & & $\begin{array}{c}\text { Aromatic } \\
\text { bands }\end{array}$ & $\mathrm{NO}_{2}{ }^{\mathrm{a})}$ & $\mathrm{CN}$ & $\mathrm{COCH}_{3}$ & $\mathrm{CH}_{3} \mathrm{~S}(=\mathrm{O})_{2}$ \\
\hline \multirow[t]{2}{*}{ 1a, $\mathrm{R}=\mathrm{NO}_{2}$} & IR & $\begin{array}{l}1598 \\
1580\end{array}$ & $\begin{array}{l}1528 \\
1350\end{array}$ & & & - \\
\hline & Raman & $\begin{array}{l}1591 \\
1577\end{array}$ & 1335 & & & 1174,1363 \\
\hline $\begin{array}{l}\mathbf{1 b}, \mathrm{R}=\mathrm{CN} \\
\mathbf{1 c}, \mathrm{R}= \\
\mathrm{COCH}_{3}\end{array}$ & $\begin{array}{l}\text { IR } \\
\text { IR }\end{array}$ & $\begin{array}{l}1577 \\
1560, \\
1604, \\
1576\end{array}$ & & $2229^{b)}$ & $1694^{\mathrm{c})}$ & - \\
\hline
\end{tabular}

By comparison, ${ }^{48}$ nitrobenzene signals were observed at 1521 and $1347 \mathrm{~cm}^{-1}$; b) benzonitrile at $2230 \mathrm{~cm}^{-1}$; c) acetophenone at $1686 \mathrm{~cm}^{-1}$ 

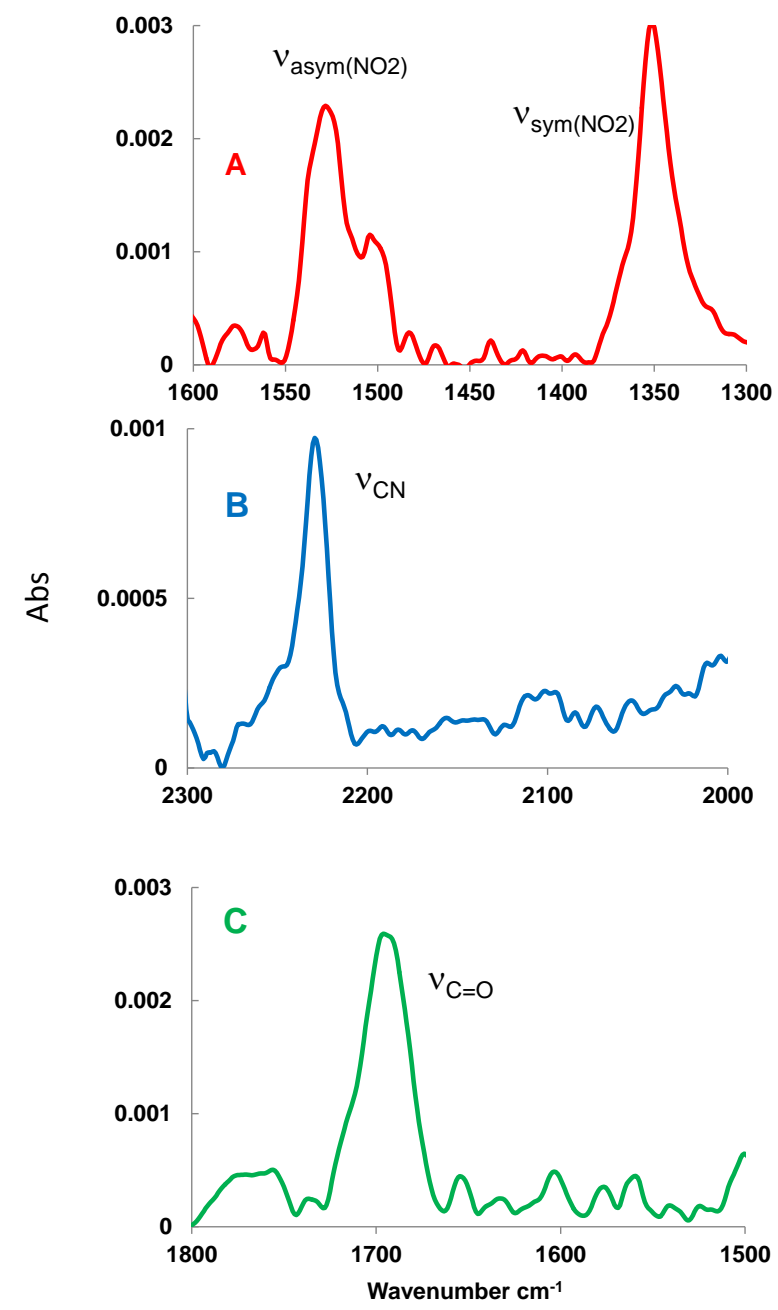

Figure 1. IRRAS spectra of $A u-\mathrm{NO}_{2}, A u-\mathrm{CN}, A u-\mathrm{COCH}_{3}$.

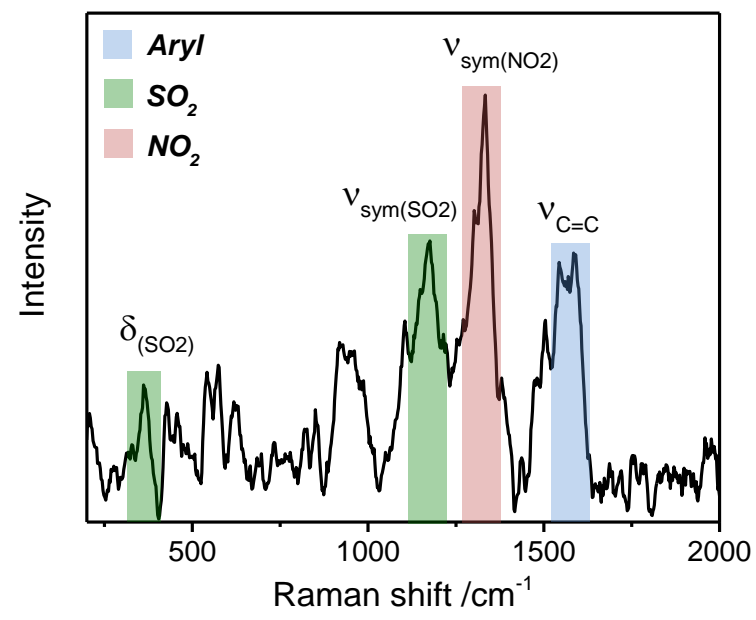

Figure 2. Surface-enhanced Raman spectrum of $A u-\mathrm{NO}_{2}$. 
XPS. The modified Au plates were also examined by XPS. The three samples present a contribution of $\mathrm{Au} 4 \mathrm{f}$, this indicates that the organic is thinner than $5-10 \mathrm{~nm}$. The observation of the signals assigned to the substituents confirms the grafting of the substituted aryl rings and of the sulfone group on the gold surface (Table 2, Figure 3). It is difficult to differentiate a grafted substituted phenyl ring from a substituted azophenyl group; however, the $\mathrm{Au}-\mathrm{N}=\mathrm{N}-\mathrm{Ar}$ structure has been observed during the grafting of diazonium salts on Au through an N1s signal at $397.5 \mathrm{eV} .{ }^{52}$ In our case, the deconvolution of the N1s peaks, does not indicate the presence of this bond except after grafting the $\mathrm{NO}_{2}$ substituted azosulfone where a very small contribution is observed at this energy. In addition, the XPS spectra indicate the presence of oxidized sulfur that corresponds to sulfone groups, but also of unoxidized sulfur similar to that of thiol SAMS, the origin of reduced sulfur results, most probably, from a reduction by the X-ray beam.

The spectrum of $\mathrm{Au}-\mathrm{NO}_{2}$ present a N1s contribution at $406.0 \mathrm{eV}$ characteristic of the nitro groups, the $\mathrm{N} 1 \mathrm{~s}$ contribution at 399.1 and $400.1 \mathrm{eV}$ (corresponding to a nitrogen and its protonated form), result respectively from i) some contamination, ii) the reduction of the nitro group under the X-ray beam, but could also be assigned to iii) azo bonds inside the film as with diazonium salts. The $\mathrm{C} 1 \mathrm{~s}$ peak presents three contributions at 284.8, 286.0 and $288.4 \mathrm{eV}$ that can be assigned to aromatic carbons but also to the carbons bonded to sulfur $\left(284.7,285.3\right.$ and 286.3 for polyethersulfone ${ }^{51}$ ). The sulfur is mostly present in its oxidized form at $166.9 \mathrm{eV}$ assigned to the sulfone group (Figure 4).

$A u$-CN presents two N1s contributions at 399.3 and $401.7 \mathrm{eV}$ that can be assigned to the cyano group but also to some contamination. Nearly equal amounts of oxidized and reduced sulfur are observed. The $\mathrm{C} 1 \mathrm{~s}$ peak also presents three contributions at 284.8, 286.3, $287.9 \mathrm{eV}) . \mathrm{Au}-\mathrm{COCH}_{3}$, the $\mathrm{C} 1 \mathrm{~S}$ peak presents three contribution at $284.8,286.2$, and $287.8 \mathrm{eV}$, the last two correspond to oxidized carbon $\mathrm{C}(=\mathrm{O})$ and $\mathrm{C}-\mathrm{S}$.

Table 2. XPS Spectra (Binding Energy eV, and \% elemental composition)

\begin{tabular}{|c|c|c|c|c|c|c|}
\hline $\begin{array}{l}A u \text {-NO }{ }_{2}, \\
\mathrm{CN}, \mathrm{COCH}_{3}\end{array}$ & $\mathrm{NO}_{2}$ & $\mathrm{CN}$ & $\mathrm{COCH}_{3}$ & $\mathbf{A u}-\mathbf{N}$ & & \\
\hline $\begin{array}{c}\mathrm{R}= \\
\mathrm{NO}_{2}\end{array}$ & $\begin{array}{c}\mathrm{N} 1 \mathrm{~s} \\
406.0 \\
(2.1)\end{array}$ & & & $\begin{array}{c}\mathrm{N} 1 \mathrm{~s} \\
397.5^{\mathrm{c})} \\
(<0.1)\end{array}$ & $\begin{array}{c}\text { S2p } \\
168.9^{d)} \\
(0.3)\end{array}$ & $\begin{array}{c}\mathrm{S} 2 \mathrm{p} \\
161.8 \mathrm{e} \\
(1.0)\end{array}$ \\
\hline $\begin{array}{l}\mathrm{R}= \\
\mathrm{CN}\end{array}$ & & $\begin{array}{c}\mathrm{C} 1 \mathrm{~s} \\
286.3^{\mathrm{a})} \\
(6.2) \\
\mathrm{N} 1 \mathrm{~s} \\
400.0 \\
5.2\end{array}$ & & ( & $\begin{array}{c}S 2 p \\
168.9^{d)} \\
(0.4)\end{array}$ & $\begin{array}{c}\mathrm{S} 2 \mathrm{p} \\
162.2^{\mathrm{e})} \\
(1.9)\end{array}$ \\
\hline $\begin{array}{c}\mathrm{R}= \\
\mathrm{COCH}_{3}\end{array}$ & & & $\begin{array}{c}\mathrm{C}(1 \mathrm{~s}) \\
287.9^{\mathrm{b}} \\
(5.5)\end{array}$ & - & $\begin{array}{c}\text { S2p } \\
168.7^{d)} \\
(0.6)\end{array}$ & $\begin{array}{c}\mathrm{S} 2 \mathrm{p} \\
162.3^{\mathrm{e})} \\
(1.3)\end{array}$ \\
\hline
\end{tabular}


a) Polyacrylonitrile N1s at $399.6 \mathrm{eV},{ }^{49}$ benzonitrile N1s a.t $399.2,{ }^{50}$ polymethacrylonitrile $\mathrm{C} 1 \mathrm{~s}$ at $286.4 \mathrm{eV}^{49}$, b) poly(3methyl-but-3-en-2-one) at $287.4 \mathrm{eV} .{ }^{51} \mathrm{c}$ ) see reference. ${ }^{52}$ d) corresponds to an oxidized sulfur, for example $\mathrm{Na}_{2} \mathrm{SO}_{4}$ at $168.4 \mathrm{eV}$ ) e) corresponds to an Au-S-R bond, for example Au-S-C ${ }_{18} \mathrm{H}_{37}$.

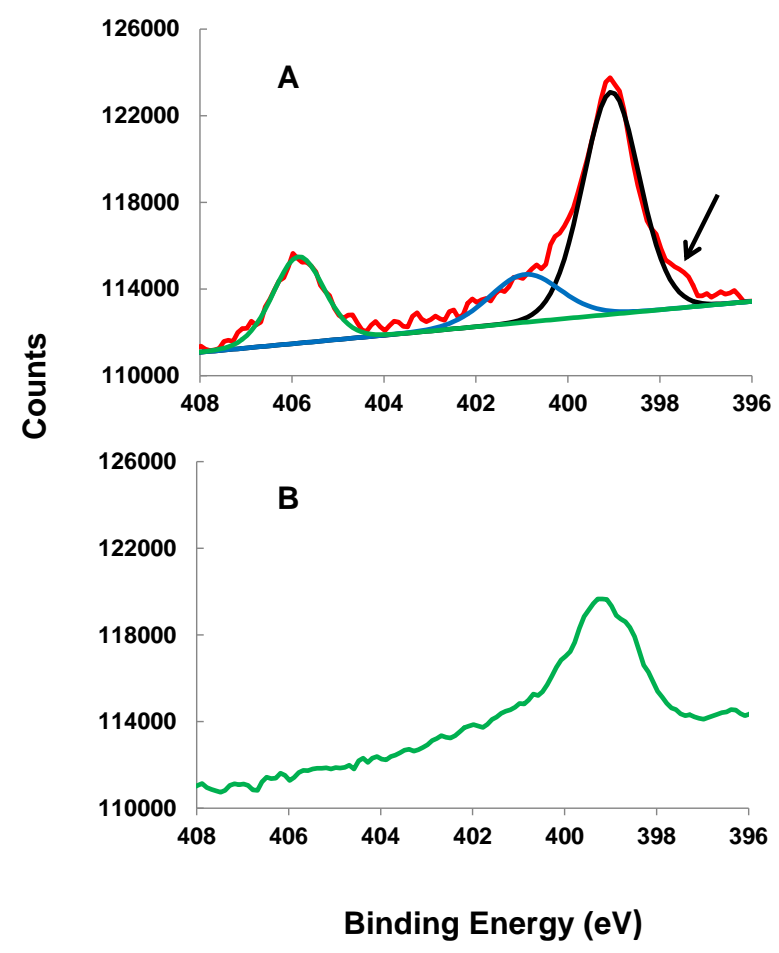

Figure 3. XPS spectra (N1s contribution) of A) $A u-\mathrm{NO}_{2}$ and B) $A u-\mathrm{CN}$.

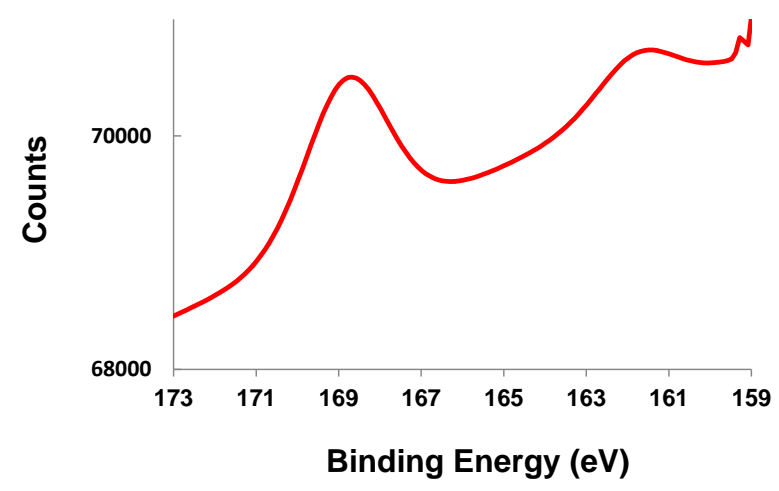

Figure 4. XPS spectra (S2p contribution) of $A u-\mathrm{NO}_{2}$

AFM. The images obtained by AFM are presented in Figure 5. The gold surface modified by 4nitroazosulfone presents a film reaching $12 \mathrm{~nm}$ on most of the surface, but on some places very high and sharp needles appear with a height up to $80 \mathrm{~nm}$. With $\mathrm{COCH}_{3}$ as the substituent these needles are much smaller reaching only $12 \mathrm{~nm}$ with a film height of 4-6 nm. These values can be compared with the length (from molecular models) of $-\mathrm{C}_{6} \mathrm{H}_{4}-\mathrm{NO}_{2},-\mathrm{C}_{6} \mathrm{H}_{4}-\mathrm{CN},-\mathrm{C}_{6} \mathrm{H}_{4}-\mathrm{COCH}_{3}$ groups $(0.68,0.73,0.80$ $\mathrm{nm}$, respectively) and indicate the formation of multilayers. If one compare the images recorded on a 
$200 \mathrm{~nm}$ scale with that of unmodified gold, the $\mathrm{Au}(111)$ domains are still visible but somewhat blurred by the grafted film.

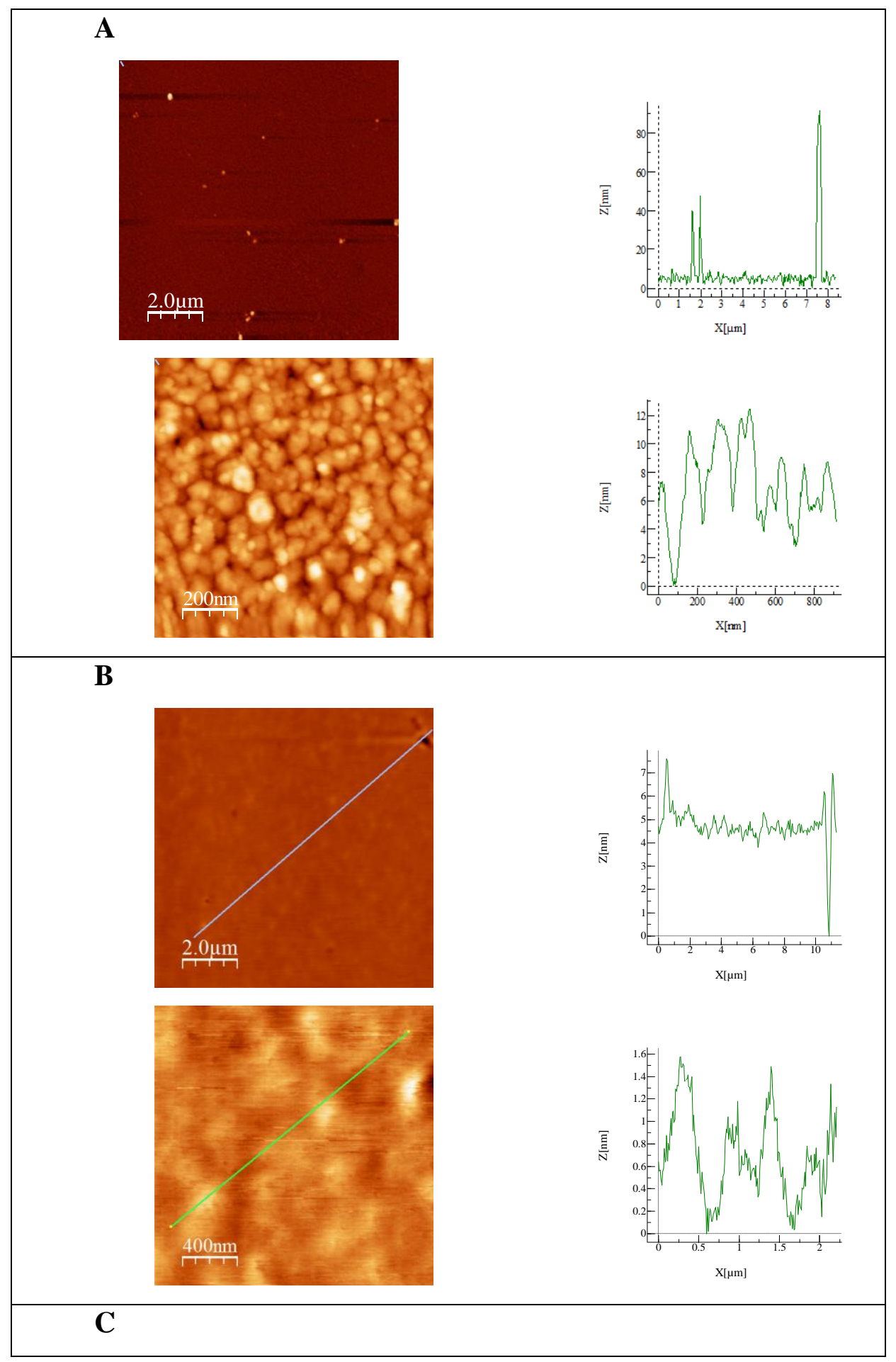




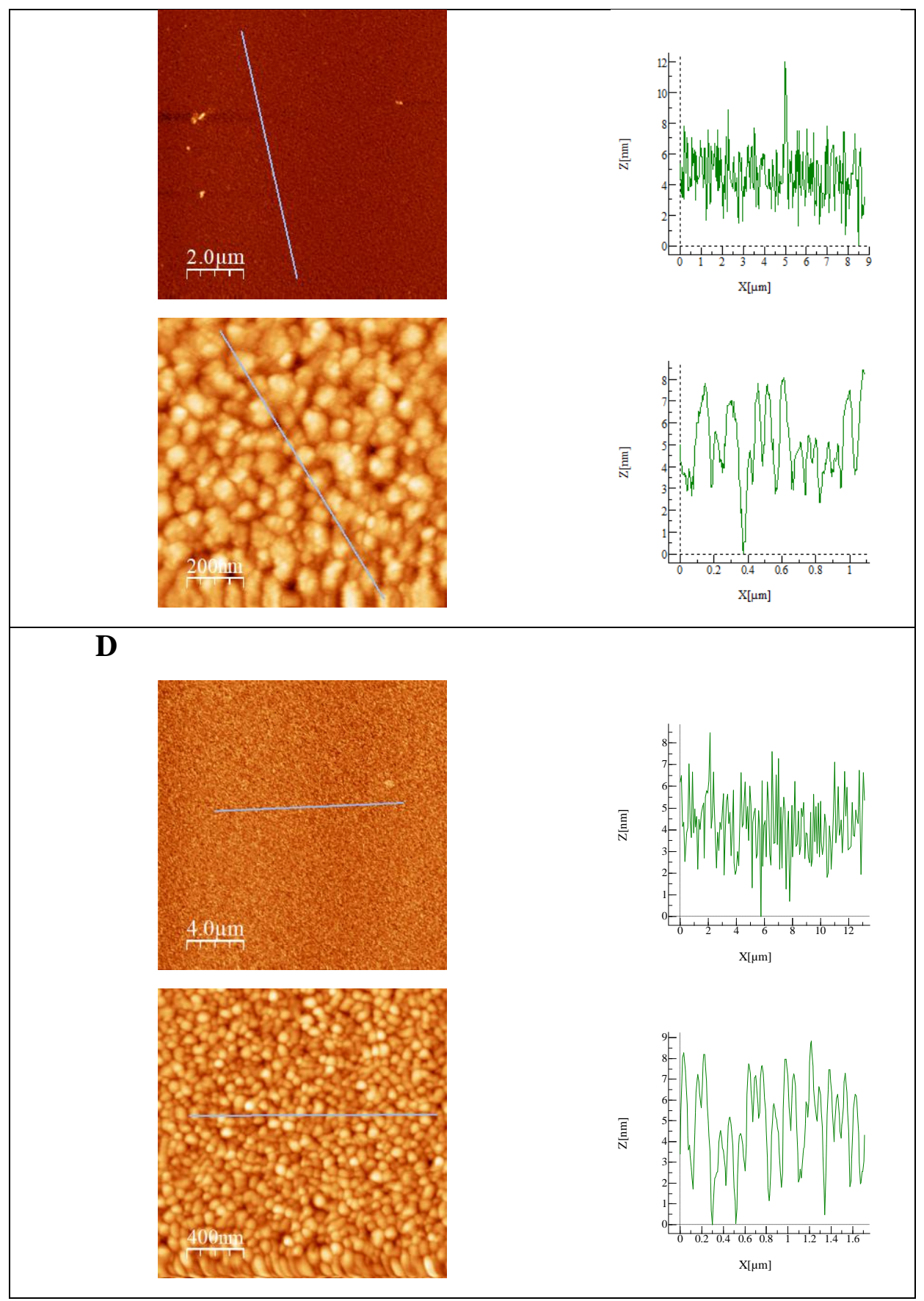

Figure 5. AFM images of the modified surfaces A) $A u-\mathrm{NO}_{2}$, B) $\left.A u-\mathrm{CN}, \mathrm{C}\right) A u-\mathrm{COCH}_{3}$, D) bare gold

The above experiments indicate that the film is a thin multilayer with very high needles, they also show that both the aryl group and the sulfone groups are part of this film. The formation of multilayers is a common feature of all radical grafting reactions but the photografting of two groups deriving from the starting compound is unexpected; therefore, the problem arises of determining the structure of the film.

The previously described mechanism permits to get a first insight into the formation of this film. Visible light irradiation of arylazo sulfones resulted in the homolytic cleavage of the N-S bond (via the ${ }^{1} \mathrm{n} \pi^{*}$ singlet excited state, (Scheme 2, paths a, b) and the generation, of the diazenyl and 
methanesulfonyl radicals. The corresponding aryl radical is obtained from $\mathrm{N}_{2}$ loss of the diazenyl radical (path c). ${ }^{33}$ Trapping by the gold surface of the diazenyl radical/ methanesulfonyl radical pair allowed the formation of the mixed functionalized surface (path d, Scheme 2). The presence of the aryl groups in the film and on the surface, has been well documented during of diazonium salts and the IRRAS spectra of surfaces grafted by arylazo sulfones indicate the presence of these groups. On the other hand, the presence of the methanesulfone moiety on the film is attested by Raman and XPS; however, we also noticed that the methanesulfonyl radical can either i) attach to the surface (path d) or ii) react on grafted aryl groups (path d') or both; to test this hypothesis we have abraded the surface with clusters of $2000 \mathrm{Ar}^{+}$ions with a total energy of $4 \mathrm{keV}$ and recorded spectra at different times (note that the total thickness of the film is analyzed). Figure 6 presents the spectra recorded after 0,60 , 120 and $180 \mathrm{~s}$ and the profile of the atomic $\%$ of the nitro group and of sulfur. The $\mathrm{NO}_{2} \%$ decreases linearly with abrasion time, while S2p \% increases slightly (due the decrease of the $\mathrm{NO}_{2} \%$ ) and decreases when reaching the surface. This indicates that the methanesulfonyl radical only reacts on the surface and not on the aryl group as in Scheme 2, path d'.
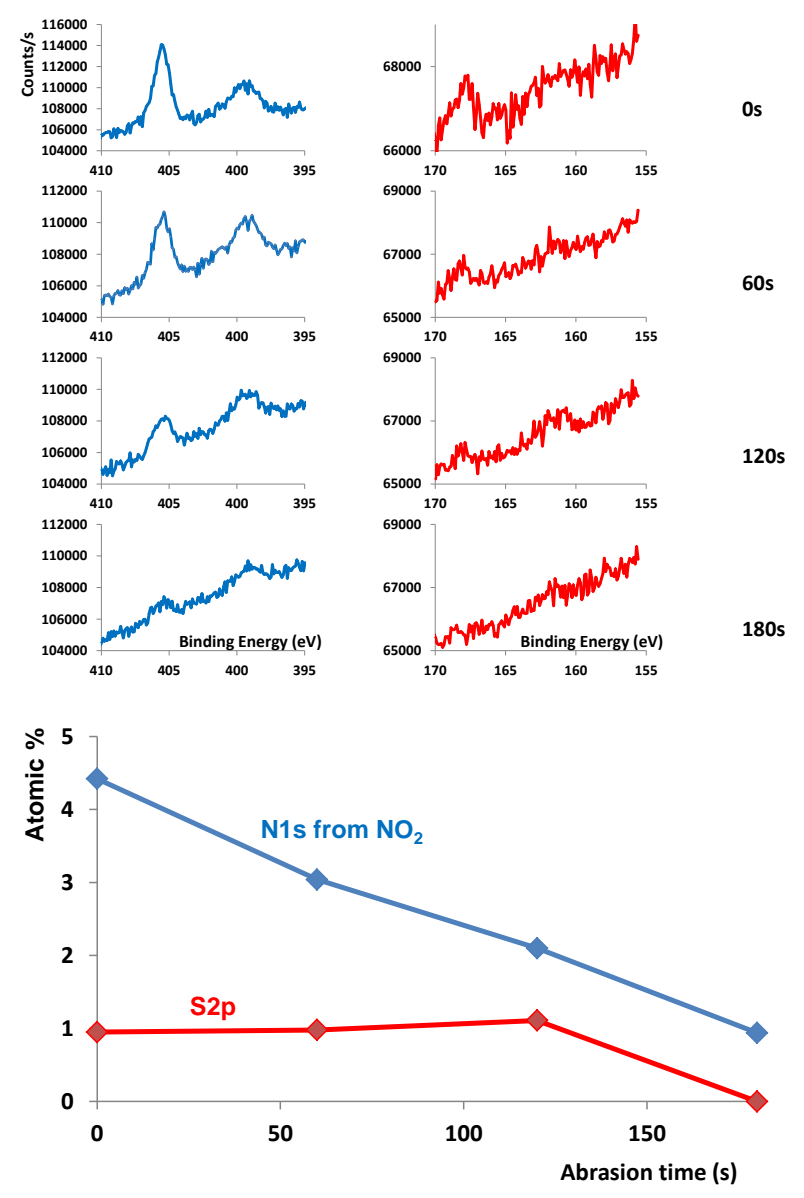

Figure 6. Abrasion of the $A u-\mathrm{NO}_{2}$ film and profile through the film of the $\mathrm{NO}_{2}$ and $\mathrm{S}$ signals 


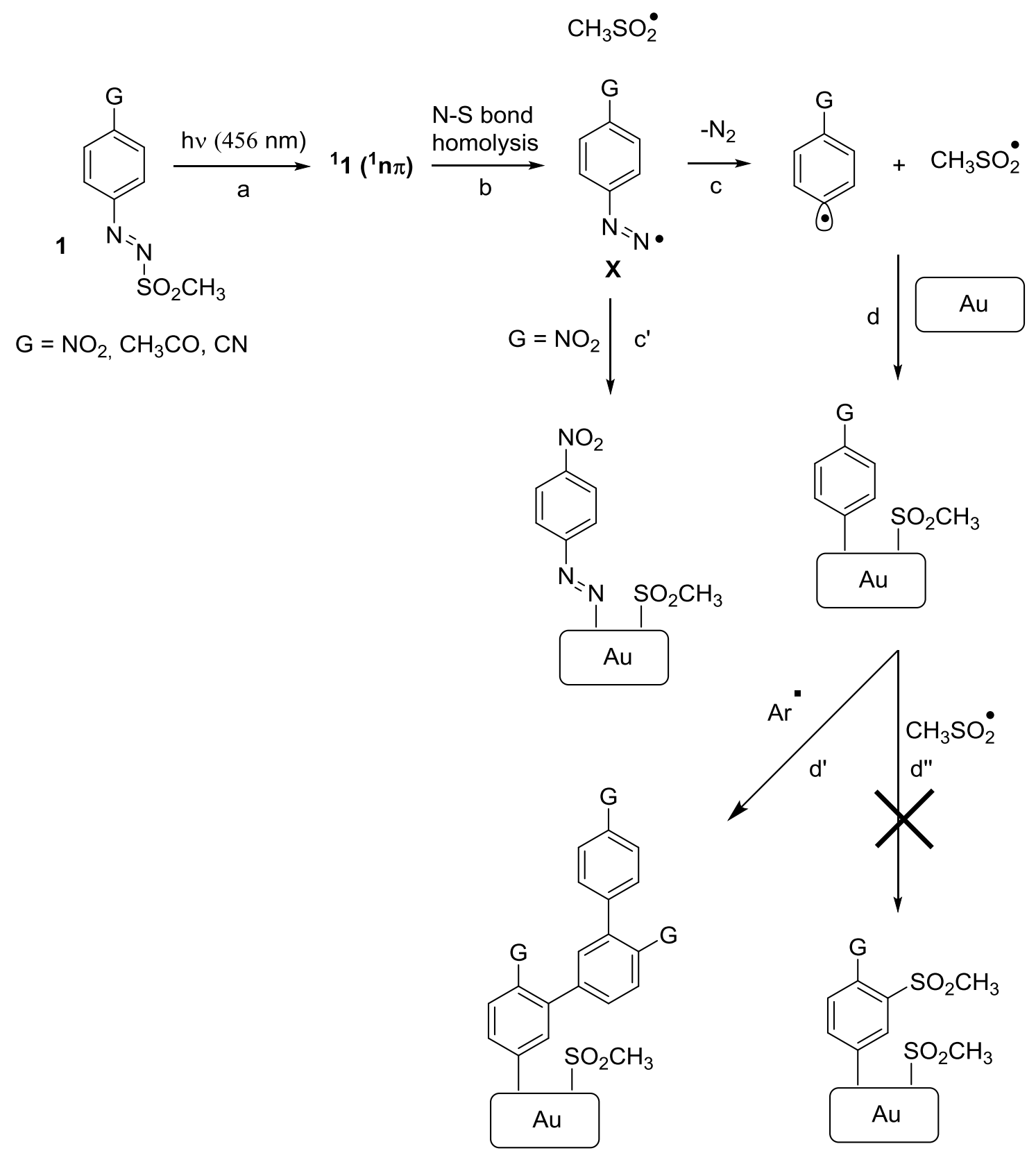

Scheme 2. The photografting mechanism of azosulfones.

In the case of 4-nitrophenylazo sulfone, early results suggested that trapping of the diazenyl radical could occur faster than $\mathrm{N}_{2}$ extrusion, and the formation of the $A u-\mathrm{N}_{2}-\mathrm{Ar}$ bond being in competition with that of the $A u$-Ar bond (path c'). We thus examined the possibility of grafting a diazenyl radical. This radical generated by photochemistry of arylthiodiazene has been observed by means of ESR analyses, the decomposition rate of the phenyl diazenyl radical was measured at $-96{ }^{\circ} \mathrm{C}: \mathrm{k}=34 \mathrm{~s}^{-1}{ }^{53}$ The bond dissociation energy of the $A u-\mathrm{N}$ bond in $A u-\mathrm{N}=\mathrm{N}-\mathrm{Ar}$ structures has been calculated by DFT methods, it is much smaller $\left(7.91 \mathrm{kcal} \mathrm{mol}^{-1}\right)^{54}$ than that of an $A u$-Ar bond ( $38.5 \mathrm{kcal} \mathrm{mol}^{-1}$ in water). Nevertheless, an Au-N bond has been characterized by an XPS signal at $397.5 \mathrm{eV}$ assigned to gold nitride during the spontaneous grafting of 4-nitrobenzenediazonium in unbuffered water. ${ }^{52}$ In the spectra above, there is no sign of $-\mathrm{N}=\mathrm{N}$ - bonds, however a very small shoulder appears at $397.6 \mathrm{eV}$ on the $\mathrm{C} 1 \mathrm{~s}$ XPS spectrum of $\mathrm{Au}-\mathrm{NO}_{2}$ (arrow in Figure $3 \mathrm{~A}$ ). Therefore $\mathrm{Au}-\mathrm{N}=\mathrm{N}$ - bonds should be present 
only in $A u-\mathrm{NO}_{2}$ (path c'). In this case trapping of the diazenyl radical occurs faster than $\mathrm{N}_{2}$ extrusion, and the formation of the Ar- $\mathrm{N}_{2}-\mathrm{Au}$ bond competes with that of the $\mathrm{Ar}-\mathrm{Au}$ bond (path d).

\section{Conclusion}

The surface modification of gold by photolysis of arylazo sulfone permits the attachment of both the substituted aryl groups and of the $\mathrm{S}(=\mathrm{O})_{2} \mathrm{CH}_{3}$ group; two groups are then grafted from a single precursor. This results from the photocleavage mechanism of azosulfones that provide two radicals, while aryl radicals react both on the surface and the first grafted groups the methanesulfonyl radical reacts only with the surface. Due to its small size it is buried in the polyphenylene oligomers film; it appears as a diluent of the aryl oligomers, a feature that is looked for when attaching large molecules to the extremities of the aryl oligomers. ${ }^{55}$

\section{Acknowledgments}

CNRS, Paris Diderot University, ANR (Agence Nationale de la Recherche) and CGI (Commissariat a l'Investissement d'Avenir) are gratefully acknowledged for their financial support through Labex SEAM (Science and Engineering for Advanced Materials and devices) ANR 11 LABEX 086, ANR 11 IDEX 0502.

\section{References}

${ }^{1}$ Bureau, C.; Haroun, F.; Henault, E. Drug eluting stent with a biodegradable release layer attached with an electro-grafted primer coating. United States Patent 9884142 to Alchimedics.

${ }^{2}$ Vergnol, G.; Renard, E.; Haroun F.; Guerin, P.; Seron, A.; Bureau, C.; Loirand, G.; Langlois V.

Electrografting of a biodegradable layer as a primer adhesion coating onto a metallic stent: in vitro and in vivo evaluation. J Mater Sci: Mater Med. 2013, 24, 2729-2739.

${ }^{3}$ Pujari, S. P.; Scheres, L.; Marcelis, A. T. M.; Zuilhof, H. Covalent surface modification of oxide surfaces. Angew. Chem., Int. Ed. 2014, 53, 6322-6356.

${ }^{4}$ Zharov, I.; Khabibullin, A. Surface-Modified Silica Colloidal Crystals: Nanoporous Films and Membranes with Controlled Ionic and Molecular Transport. Acc. Chem. Res. 2014, 47, 440-449.

5 Chandekar, A.; Sengupta, S. K.; Whitten, J. E. Thermal stability of thiol and silane monolayers: A comparative study. Appl. Surf. Sci. 2010, 256, 2742-2749.

${ }^{6}$ Sahoo, Y.; Pizem, H.; Fried, T.; Golodnitsky, D.; Burstein, L.; Sukenik, C. N.; Markovich, G. Alkyl Phosphonate/Phosphate Coating on Magnetite Nanoparticles: A Comparison with Fatty Acids. Langmuir, 2001, 17, 7907-7911.

${ }^{7}$ Collins, G.; O’Dwyer, C.; Morris, M.; Holmes, J. D. Palladium-Catalyzed Coupling Reactions for the Functionalization of Si Surfaces: Superior Stability of Alkenyl Monolayers. Langmuir 2013, 29, 11950-11958. 
${ }^{8}$ Fabre, B. Ferrocene-Terminated Monolayers Covalently Bound to Hydrogen-Terminated Silicon Surfaces. Toward the Development of Charge Storage and Communication Devices. Acc. Chem. Res. 2010, 43, 15091518.

${ }^{9}$ Ssenyange, S; Anariba, F. D.; Bocian, F.; McCreery, R. L. Covalent Bonding of Alkene and Alkyne Reagents to Graphitic Carbon Surfaces. Langmuir 2005, 21, 11105-11112.

10 Love, J. C.; Estroff, L. A.; Kriebel, J. K.; Nuzzo, R. G.; Whitesides, G. M. Self-Assembled Monolayers of Thiolates on Metals as a Form of Nanotechnology. Chem. Rev. 2005, 105, 1103-1170.

${ }^{11}$ Berisha, A.; Chehimi, M. M.; Pinson, J.; Podvorica, F.I. Electrode surface modification using diazonium salts, in: A.J. Bard, C.G. Zoski (Eds.), Electroanalytical Chemistry, 26 CRC Press, Boca Raton, FL, 2016.

12 Bélanger, D.; Pinson, J. Electrografting: a powerful method for surface modification. Chem. Soc. Rev. 2011, 40, 3995-4048.

${ }^{13}$ Frick, E.; Schweigert, C.; Noble, B. B.; Ernst, H. A.; Lauer, A.; Liang, Y.; Voll, D.; Coote, M. L.; Unterreiner, A.-N.; Barner-Kowollik, C. Toward a quantitative description of radical photoinitiator structure-reactivity correlations, Macromolecules 2016, 49, 80-89.

${ }^{14}$ Qi, Y.; Chen, S.; Zhang, J. Fluorine modification on titanium dioxide particles: Improving the anti-icing performance through a very hydrophobic surface. Appl. Surf. Sci. 2019, 476, 161-173.

15 Yousaf, A.; Farrukh, A.; Oluz, Z.; Tuncel, E.; Duran, H.; Doğan, S. Y.; Tekinay, T.; ur Rehman, H.; Yameen, B. UV-light assisted single step route to functional PEEK surfaces. React. Funct. Polym. 2014, 83, 70-75;

${ }^{16}$ Prucker, O.; Rühe, J. Synthesis of poly(styrene) monolayers attached to high surface area silica gels through self-assembled monolayers of azo initiators. Macromolecules 1998, 31, 592-601.

${ }^{17}$ Rohr, T.; Hilder, E. F.; Donovan, J. J.; Svec, F.;Fréchet, J. M. J. Photografting and the Control of Surface Chemistry in Three-Dimensional Porous Polymer Monoliths. Macromolecules, 2003, 36, 1677-1684.

18 Gam-Derouich, S.: Lamouri, A.; Redeuilh, C.; Decorse, P.; Maurel, F.; Carbonnier, B.; Beyazit, S.; Yilmaz, G.; Yagci, Y.; Chehimi, M. M. Diazonium salt-derived 4-(dimethylamino)phenyl groups as hydrogen donors in surface-confined radical photopolymerization for bioactive poly(2-hydroxyethyl methacrylate) grafts. Langmuir 2012, 28, 8035-8045.

${ }^{19}$ March's Advanced Organc Chemistry, M. B. Smith, J. March, Wiley-Interscience, Weinheim, 2007, $6^{\text {th }}$ edition, pp 287.

${ }^{20}$ Wentrup, C. Carbenes and Nitrenes: Recent Developments in Fundamental Chemistry Angew. Chem. Int. Ed. 2018, 57, 11508-11521.

${ }^{21}$ Awenat, K. M.; Davis, P. J.; Moloney, M. G.; Ebenezer, W. Titre Chem. Commun. 2005, 990.

${ }^{22}$ Busson, M.; Berisha, A.; Combellas, C.; Kanoufi, F.; Pinson, J. Chem. Commun. 2011, 47, 12631-12633.

23 Bouriga, M.; Chehimi, M. M.; Combellas, C.; Decorse, P.;Kanoufi, F.; Deronzier, A.; Pinson, J. Sensitized Photografting of Diazonium Salts by Visible Light. Chem. Mater. 2013, 25, 90-97. 
${ }^{24}$ Médard, J.; Combellas, C.; Kanoufi, F.; Pinson, J.; Chauvin, J.; Deronzier.A. Patterning Surfaces through Photografting of Iodonium Salts. J. Phys. Chem. C 2018, 122, 19722-19730.

${ }^{25}$ Garcia, A.; Hanifi, N.; Jousselme, B.; Jégou, P.; Palacin, S.; Viel, P.; Berthelot, T. Polymer Grafting by Inkjet Printing: A Direct Chemical Writing Toolset. Adv. Funct. Mater. 2013, 23, 3668-3674. Erreur! Signet non défini.

${ }^{26}$ Schroll, P.; Fehl, C.; Dankesreiter, S.; König, B. Photocatalytic surface patterning of cellulose using diazonium salts and visible light. Org. Biomol. Chem. 2013, 11, 6510-6513.

27 Zhou, Y.; Bai, Y.; Wei J. Ultraviolet Grafting of Styrene and Maleic Anhydride on PolyethyleneTerephthalate Film. Appl. Polym. Sci. 2006, 102, 285-288.

28 Jianping, D.; Wantai Y. Surface Photografting Polymerization of Vinyl Acetate, Maleic Anhydride, and Their Charge-Transfer Complex.VIII. Charge-Transfer Complex Appl. Polym. Sci. 2006, 99, 2710-2720.

${ }^{29}$ Zhu, X.; He, B.; Zhao, C.; Ma, Y.; Yang W. Separated Immobilization of Incompatible Enzymes on Polymer Substrate via Visible Light Induced Living Photografting Polymerization. Langmuir 2017, 33, $5577-5584$.

${ }^{30}$ Gui, A. L.; Yau, H. M.; D, S.; Chockalingam, M.; Harper, J. B.; Gooding, J. J. Using Supramolecular Binding Motifs to Provide Precise Control over the Ratio and Distribution of Species in Multiple Component Films Grafted on Surfaces: Demonstration Using Electrochemical Assembly from Aryl Diazonium Salts. Langmuir 2013, 29, 4772-4781.

${ }^{31}$ Santos, L.; Ghilane, J.; Lacroix, J. C. Formation of Mixed Organic Layers by Stepwise Electrochemical Reduction of Diazonium Compounds. J. Am. Chem. Soc. 2012, 134, 5476-5479.

${ }^{32}$ Lee, L.; Brooksby, P. A.; Leroux, Y. R.; Hapiot, P.; Downard, A. J. Mixed Monolayer Organic Films via Sequential Electrografting from Aryldiazonium Ion and Arylhydrazine Solutions. Langmuir 2013, 29, 3133-3139.

${ }^{33}$ Arnold, C. L.; Eyckens, D. J.; Servinis, L.; Nave, M. D.; Yin, H.; Marceau, R. K. W.; Pinson, J.; Demir, B.; Walsh, T. R.; Henderson, L. C. Simultaneously increasing the hydrophobicity and interfacial adhesion of carbon fibres: a simple pathway to install passive functionality into composites. J. Mater. Chem. A, 2019, 7, 13483-13494.

${ }^{34}$ Gross, A. J.; Yu, S. S. C.; Downard, A. J. Two-Component Mixed and Patterned Films on Carbon Surfaces through the Photografting of Arylazides. Langmuir 2010, 26, 7285-7292.

${ }^{35}$ Crespi, S.; Protti, S.; Fagnoni, M. Wavelength Selective Generation of Aryl Radicals and Aryl Cations for Metal-free Photoarylations. J. Org. Chem. 2016, 81, 9612-9621.

${ }^{36}$ Malacarne, M.; Protti, S.; Fagnoni, M. A visible light driven, metal-free route to aromatic amides via radical arylation of isonitriles. Adv. Synth. Catal. 2017, 359, 3826-3830.

${ }^{37}$ Dossena, A.; Sampaolesi, S.; Palmieri, A.; Protti, S.; Fagnoni, M. Visible light promoted metal- and photocatalyst-free synthesis of allylarenes. J. Org. Chem. 2017, 82, 10687-10692. 
38 Onuigbo, L.; Raviola, C.; Di Fonzo, A.; Protti, S.; Fagnoni, M. Sunlight-driven synthesis of triarylethylenes (TAEs) via metal-free Mizoroki-Heck-type coupling. Eur. J. Org. Chem. 2018, 5297-5303.

39 Sauer, C.; Liu, Y.; De Nisi, A.; Protti, S.; Fagnoni, M.; Bandini, M. Photocatalyst-free, visible light driven, gold promoted Suzuki synthesis of (hetero) biaryls. ChemCatChem 2017, 9, 4456-4459.

${ }^{40}$ Blank, L.; Fagnoni, M.; Protti, S.; Rueping, M. Visible Light-Promoted Formation of C-B and C-S Bonds under Metal- and Photocatalyst-Free Conditions. Synthesis 2019, 51, 1243-1252.

${ }^{41}$ Liu, Q.; Wang, L.; Yue, H.; Li, J.-S.; Luo, Z.; Wei, W. Catalyst-free visible-light-initiated oxidative coupling of aryldiazo sulfones with thiols leading to unsymmetrical sulfoxides in air. Green Chem. 2019, 21, 1609-1613.

${ }^{42}$ Crespi, S.; Protti, S.; Fagnoni, M. Wavelength Selective Generation of Aryl Radicals and Aryl Cations for Metal-free Photoarylations. J. Org. Chem. 2016, 81, 9612-9621.

43 Malacarne, M.; Protti, S.; Fagnoni, M. A visible light driven, metal-free route to aromatic amides via radical arylation of isonitriles. Adv. Synth. Catal. 2017, 359, 3826-3830.]

${ }^{44}$ Socrates G. Infrared and Raman Characteristic Group Frequencies. $3^{\text {rd }}$ Edition, John Wiley and Sons, Weinheim, 2001.

45 Bazylewski, P.; Divigalpitiyab, R.; Fanchini G. In situ Raman spectroscopy distinguishes between reversible and irreversible thiol modifications in L-cysteine, RSC Adv., 2017, 7, 2964-2970.

${ }^{46}$ Wang, G.; Leus, K.; Couck, S.; Tack, P.; Depauw, H.; Liu, Y.-Y.; Vincze, L.; Denayer, J. F. M.; Van Der Voort, P. Enhanced gas sorption and breathing properties of the new sulfone functionalized COMOC-2 metal organic framework, Dalton Trans. 2016, 45, 9485-9491.

${ }^{47}$ Diaz-Fleming, G.; Célis, F.; Fredes, C.; Campos-Vallette, M.; Aliaga, A.E.; Koch, R. Surface-enhanced Raman scattering and density functional theory studies of bis(4-aminophenyl)sulfone, J. Raman Spectrosc. 2010, 41, 160-166.

${ }^{48}$ SDBSWeb : https://sdbs.db.aist.go.jp (National Institute of Advanced Industrial Science and Technology, date of access 2019/05:14)

${ }^{49}$ Beamson, G.; Briggs, D. High Resolution XPS of Organic Compounds. The Scientia ESCA 300 Database 1992).

${ }^{50}$ Lindberg, B. J.; Hedman, J. Chemica Sripta 1975, 7, 155.

${ }^{51}$ NIST X-ray Photoelectron Spectroscopy Database, NIST Standard Reference Database 20, Version 4.1

${ }^{52}$ Mesnage, A. ; Lefèvre, X. ; Jégou, P. ; Deniau G. ; Palacin, S. Spontaneous Grafting of Diazonium Salts: Chemical Mechanism on Metallic Surfaces, Langmuir 2012, 28, 11767-11778

${ }^{53}$ Suehiro, T.; Masuda, S.; Nakausa, R.; Taguchi, M. Mori A.; Koike, A.; Date, M. Decay Reactions of Aryldiazenyl Radicals in Solution. Bull. Chem. Soc. Jpn. 1987, 60, 3321-3330. 
${ }^{54}$ Berisha, A.; Combellas, C.; Kanoufi, F.; Decorse, P.; Oturan, N.; Médard, J; Seydou, M.; Maurel, F.; Pinson, J. Some Theoretical and Experimental Insights on the Mechanistic Routes Leading to the Spontaneous Grafting of Gold Surfaces by Diazonium Salts, Langmuir 2017, 33, 8730-8738.

${ }^{55}$ Liu, G.; Gooding, J. J. An Interface Comprising Molecular Wires and Poly(ethylene glycol) Spacer Units Self-Assembled on Carbon Electrodes for Studies of Protein Electrochemistry. Langmuir 2006, 22, 74217430 